\title{
АНТИЦИПАЦИОННЫЙ ТРЕНИНГ КАК МЕТОД ПРОГНОЗИРОВАНИЯ МЕЖЛИЧНОСТНЫХ КОНФЛИКТОВ В ПОДРОСТКОВОЙ СРЕДЕ
}

\begin{abstract}
Аннотация. Предметом исследования является антиципационная состоятельность личности подростка как условие предупреждения конфликтных ситуаций. В статье рассмотрена антиципация личности, как способность принимать те или иные решения и действовать с определенным временно-пространственным упреждением в отношении ожидаемых и будущих событий, развитие многовариантного типа мышления. Рассматривая прогностические способности в предупреждении межличностных конфрликтов среди подростков, в работе делается особый упор на личностно-ситуативную и временную антципационную состоятельность. Развитие способности предвосхищения конфлликта у подростков способствует развитию конструктивного и бесконфрликтного метода общения и является важным фактором в формировании личности подростка.

В ходе проведения исследования были использованы психодиагностические методы: тест К. Томаса по выбору стратегий в конфликте, тест антиципационной состоятельности (прогностической компетентности) В.Д. Менделевича, разработанная методика «Прогнозирование межличностных конфликтов». В качестве экспериментального метода был использован разработанный антиципационный тренинг прогнозирования межличностных конфликтов.

Научная новизна характеризуется тем, что впервые в психологической науке антиципационная состоятельность изучается в аспекте подростковой конфликтности. Новизна заключается также в разработке программы антиципационного тренинга, в ходе которой наблюдается, что обучение подростков антиципационным способностям будет способствовать развитию умения прогнозировать межличностные конфликты среди сверстников и нейтрализовывать их на стадии формирования. Групповая работа, посредством моделирования конфлликтных ситуаций, наглядно показала свою результативность в формирование многовариантного типа мышления у подростков и была подтверждена статистически-верными данными.

Ключевые слова: антиципация, антиципационный тренинг, прогнозирование, предупреждение конфликта, межличностный конфликт, антиципационная состоятельность, прогностическая компетентность, предвосхищение, подростковый конфликт, бесконфликтное общение.
\end{abstract}

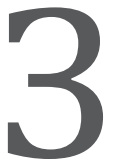

начимость антиципационных (прогностических) способностей в развитии личности подростка подчеркивали множество отечественных и зарубежных ученых, среди которых Б.Ф. Ломов, Е.Н. Сурков, А.К. Маркова, Х. Ремшмидт, Сергиенко Е.А. и др. В пубертатный период у подростка активно развивается такое качество личности как предвосхищающий самоконтроль, способствующий коррекции поведения и деятельности. Он способствует развитию умения предвидеть последствия предполагаемых действий для себя, сверстников, взрослых и утвердиться в правильности намеченных действий, либо изменить свое решение как несоответствующее ожиданиям окружающих.
При сильной мотивации подростка и потребности занять достойное положение в группе сверстников подросток способен прогнозировать действенность выбранного им приема. Если поступок произвел отрицательный эффект в группе, то прибегать повторно к такому методу подросток не станет, иначе обстоят дела с положительным эффектом.

Подростки прогнозируют реакции окружающих на те поступки, которые могут способствовать удовлетворению мотивирующих потребностей.

Умение подростка прогнозировать эмоциональные отношения вырабатывают в его личности такое качество как предвосхищающий самоконтроль, который обеспечивает коррекцию поведе- 
ния и деятельности на все более отодвинутый во времени результат.

Как показывает большинство научных экспериментов, при целенаправленном обучении уровень антиципационных способностей и способностей к прогнозированию развивается намного интенсивней ${ }^{1}$. В исследованиях А.К. Марковой изучавшей способность самоконтроля речевых высказываний у подростков, было выявлено, что до обучения среднее количество высказываний, которые являлись прогнозирующим контролем составляло 1,1 ; после обучения - $13,4^{2}$.

Рассмотрев особенности прогнозирования при построении и развитии гипотез в подростковом возрасте, по сравнению с младшим школьным, значительно совершенствуется аналитико-синтетическая деятельность, благодаря которой возможно достаточно полное использование заданных условий для построения гипотез. В структуре прогнозирования достаточно важным моментом в подростковом возрасте является такой показатель мышления как гибкость и вариативность гипотез, другим словом способность к перестройке гипотез в ходе поиска решения под влиянием оценки гипотез, способность к изменению направления поиска.

Характер процесса обработки информации при прогнозировании в подростковом возрасте существенно выше, чем в младшем школьном. Подросток рассматривает все возможные связи и отношения между фактами, вырабатывает различные варианты решения и составляет прогноз еще до принятия решения и выработки процесса действий. Значительную роль прогнозирование в подростковом возрасте оказывает на принятие решения и подросток осознает, что принятие решения сопряжено с ответственностью за его последствия ${ }^{3}$.

На сегодняшний день актуальным остается вопрос о том, возможно ли обучить подростков прогнозировать межличностные конфликты, обнаруживать предпосылки предконфликтной ситуации и нейтрализовать их в период становления.

На первом этапе настоящего исследования были обследованы 224 подростка (учащиеся 9-11 классов)

\footnotetext{
1 Сергиенко Е.А. Раннее когнитивное развитие: новый взгляд. М.: ИП РАН, 2006. 207 с.

2 Маркова А.К. Психология усвоения языка как средства общения. М.: Просвещение, 1974. 225 с.

3 Кулюткин Ю.Н. Индивидуальные различия в мыслительной деятельности взрослых и учащихся. М.: Педагогика, 1971. 112 c.
}

гимназии № 90 г. Казани по методикам стратегий выхода из конфликта К. Томаса и тесту антиципационной состоятельности (прогностической компетентности) В.Д. Менделевича. При статистической обработке данных первичного исследования было выявлено, что преобладает взаимосвязь между стратегиями выхода из конфликта и антиципационной состоятельностью $(\mathrm{r}=0,153(\mathrm{p}>0,05))^{4}$. Это позволяет говорить о том, что формирование у подростков высокого уровня прогностической компетентности посредством обучения навыкам прогнозирования, должно способствовать уменьшению уровня конфликтности в подростковой среде.

Опираясь на правила, и принципы групповой работы была разработана программа антиципационного тренинга для предупреждения межличностных конфликтов, направленная на повышение уровня прогностических способностей. За основу был взят тренинг антиципационной состоятельности, разработанный В.Д. Менделевичем, проводимый в виде индивидуальных и групповых занятий, направленный на выработку стратегии многовариантного прогнозирования и «антиципирующего совладания», основным девизом которого является «надейся на лучшее, но готовься к худшему» ${ }^{5}$. Данный тренинг был адаптирован к обучению подростков предупреждению межличностных конфликтов в своей среде. Разработанная программа тренингового занятия представляет собой групповой тип работы, где подростком проигрываются реальные жизненные ситуации межличностных конфликтов в искусственно-созданной социально-психологической среде и на практике им отрабатывается и закрепляется умение прогнозирования. Программа тренинга имеет продолжительность 1,5-2 часа и рассчитана на группы от 15 до 25 человек.

Целью тренинга являлось обучение подростков способности прогнозировать события для формирования антиципационной состоятельности, позволяющей предупреждать возникновение межличностных конфликтов в подростковой среде, выделять существенные признаки и предпо-

\footnotetext{
4 Сиразиев М.Р. Антиципационная состоятельность личности подростка при разрешении конфликтных ситуаций // Современные проблемы науки и образования. 2014. № 2 (URL: http://www.science-education.ru/116-12436).

Менделевич В.Д. Тест антиципационной состоятельности и прогностической компетентности-экспериментально-психологической оценки готовности к невротическим расстройствам // Социально-клиническая психиатрия. 2003. № 1. С. 35-40.
} 


\section{Психотехника}

сылки предконфликтной ситуации и разрешать ее на стадии первичного формирования. Предполагалось, что в результате тренинга должен повышаться уровень личностно-ситуативной и временной антиципационной состоятельности и улучшаться умение видеть предпосылки к появлению предконфликтной ситуации.

В написании программы тренинга учитывалось то, что вид групповой работы может быть результативным не для каждого типа личности, высокую эффективность конкретному типу личности может принести и индивидуальное консультирование.

Программа тренинга включала 11 тренинговых упражнений, в ходе которых подростка обучали основным навыкам прогнозирования, умению анализировать невербальные каналы передачи информации и вводили его в искусственно-созданную предконфликтную ситуацию, где при групповом обсуждении он выводил для себя оптимальный и бесконфликтный способ решения ситуации.

Основная задача, преследуемая в процессе выполнения тренинговых упражнений - формирование бесконфликтной коммуникативной компетентности у подростка. Также в тренинговой программе был модифицирован тест фрустрационных реакций Розенцвейга, адаптированный под групповой тип работы, для определения в процессе группового общения наиболее острых и проблемных ситуаций для подростка.

Тренинг был апробирован на группе подростков в количестве 20 человек в возрасте от 14 до 16 лет, для того чтобы сформировать базу основных упражнений. После апробации тренинга была выявлена потребность в упражнениях, обучающих умению прогнозировать невербальные каналы передачи информации. Учитывая необходимую потребность дополнительно было включено в программу тренинга проективное упражнение «Понять партнера», направленное на определение эмоционального состояния личности по мимическим проявлениям, языку телодвижений, различным сигнальным и знаковым системам.

На следующем этапе, когда тренинг был окончательно сформирован, работа проводилась с первичной выборкой, то есть на подростках гимназии № 90 г. Казани. Тренинг проходил около 2,5 часов. Из всей выборки испытуемых были сформированы 9 групп по 20-25 человек. В ходе проведения тренинга можно было заметить, что наибольший интерес подростки проявляли к упражнениям, способствующим развитию анализа поведения людей по невербальным каналам информации. По мнению подростков, изучение невербальных средств общения поможет обнаруживать предпосылки к появлению конфликтных ситуаций. В процессе группового обсуждения было выявлено, что большинство конфликтогенных факторов, приводящих к инциденту и в последствии к конфликту происходят из-за низкого уровня коммуникативной компетентности подростков, неумения объективно и бесконфликтно донести информацию или претензию до оппонента. Ролью подкрепляющего и стимульного инструмента здесь послужило упражнение «Я-высказывания», с помощью которого подростки на практике отрабатывали реальные конфликтные ситуации, свойственные их возрасту, в искусственно-созданной социально-психологической среде. При помощи проб и ошибок, а так же методом группового решения выводили наиболее конструктивную и верную модель поведения по прогнозированию и нейтрализации конфликтогенных факторов в общении.

Как выяснилось в ходе проведения тренинга в результате рефлексии по проведенным упражнениям у большинства подростков преобладали выраженный низкий уровень самокритичности, невозможность признать свои ошибки, вследствие чего, неумение рационально оценить ситуацию и последствия принимаемых ими решений. В ходе группового решения вопроса, «губительным», по словам подростка, становилась та ситуация, где ему приходилось признать себя неправым, отказаться от своих убеждений на виду у своих сверстников. Для развития умения оценки ситуации использовалось тренинговое упражнение «Инстинкты конфликта» с воссозданием проблемной ситуации, в которой выявлялись наиболее оптимальный и конструктивный метод взаимодействия без негативно-настроенных тенденций на оппонента.

Одним из наиболее интересных упражнений в тренинге являлся тест фрустрационных реакций Розенцвейга, адаптированный в ролевую игру «Отработка конфликта», которая проходила в порядке группового обсуждения и моделирования наиболее проблемных ситуаций. В ходе данного упражнения были сформированы наиболее проблемные ситуации для, а именно, ситуации препятствия «сверх я», где подросток служил объектом обвинения и его призывали к ответственности (рисуночные ситуация 2, 10, 16 и др.) Большинство других ситуаций в тесте, ситуации препятствия «я», в которых подросток сталкивался с ситуациями, «сби- 
вавшими с толку», решались наиболее быстрыми способами и не вызывали особой эмоциональной реакции у подростков.

У большинства подростков (более 60\%) наблюдалась экстрапунитивная направленность реакций, что выражалось в повышенной требовательности к окружающим и недостаточной самокритичности. Наличие экстрапунитивности проявлялось в самой ситуации, которая представала перед подростком как стрессовая, вследствие чего и активировались эго-защитные механизмы. У второй половины подростков (40\% испытуемых) в подобных ситуациях наблюдался интрапунитивный тип реакции, где субъект, признавая свою ответственность, брались самостоятельно исправить положение, компенсировать потери другому лицу. Реакции импунитивной направленности, характеризовавшиеся стремлением сгладить конфликт, наблюдалось лишь у 10\% испытуемых подростков.

После тренинга подростки были вновь протестированы по выбранным методикам. Дополнительно был разработан опросник «Прогнозирование межличностного конфликта» для количественного анализа умения прогностических способностей.

По результатам методики К. Томаса было выявлено, что после проведения тренинга значительно увеличился выбор адаптивной стратегии сотрудничества $(57,2 \%$ подростков), снизился уровень выбора стратегии соперничества $(15,3 \%$ испытуемых подростков). Стратегию приспособления использовали 12,2\% испытуемых подростков и 15,3\% использовали относительно-адаптивную стратегию компромисса. Стоить заметить, что после проведения тренинга подростки перестали выбирать неадаптивную стратегию избегания конфликта, до проведения тренинга ее использовали 18\% испытуемых подростков. Результаты выбора стратегий поведения в конфликтной ситуации до и после тренинга представлены на рис. 1.

По результатам теста антиципационной состоятельности В.Д. Менделевича, после проведения тренинга значительно вырос уровень общей антиципационной состоятельности (77,5\% испытуемых подростков) и уровень личностно-ситуативной антиципационной состоятельности (80,4\% испытуемых), уровень временной антиципационной состоятельности остался почти неизменным (54,3\% испытуемых подростков). Данные изменения позволяют утверждать, что разработанный антиципационный тренинг подтвердил свою эффективность на практике и действительно является методом об-

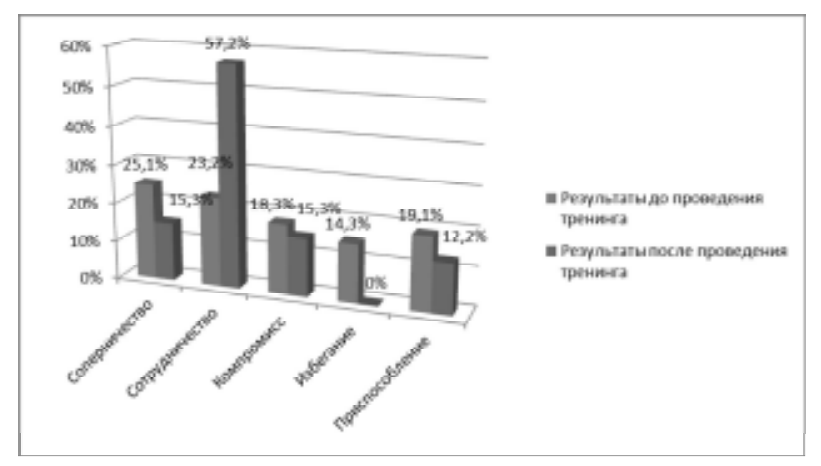

Рис. 1. Показатель выбора стратегий выхода из конфликта до и после тренинга

учения подростков прогностическим способностям, а именно умения предвидеть развитие событий, явлений и действий. По результатам теста становится ясным, что тренинг направлен на развитие коммуникативного уровня антиципации, то есть способности прогнозировать жизненные события и ситуации, и не затрагивает хронометрологические способности подростков, то есть способность прогнозировать течение и точно распределять время.

По результатам разработанного опросника «Прогнозирование межличностного конфликта» было выявлено, что после проведенного тренинга большая часть подростков (75,6\% испытуемых) в ситуации спора с оппонентом не начинают действовать без полного анализа ситуации и обстоятельств. После проведенных упражнений в тренинге, большинство испытуемых (67,8\%) стали обращать внимание на невербальные компоненты в межличностном общении и 33,5\% подростков обращают внимание на эмоциональное отношение собеседника к себе. Также результативность тренинга подтверждается выбором большинства испытуемых многовариантного типа мышления (81,4\% подростков) при разрешении проблемных ситуаций. При оценке прогнозирования возможны вариантов исхода событий в предконфликтной ситуации, большинство подростков (65\% испытуемых) могут смоделировать последствия развития ситуации и принять правильное решение для нейтрализации конфликта. Подростки, выбирающие неадаптивный тип стратегии соперничества не могут управлять своим эмоционально-волевым состоянием и не задумываются о долгосрочных последствиях принимаемых решений. При анализе собеседника в процессе общения большая часть подростков (69\% испытуемых) может определить причинно-следственные связи, по которым чело- 


\section{Психотехника}

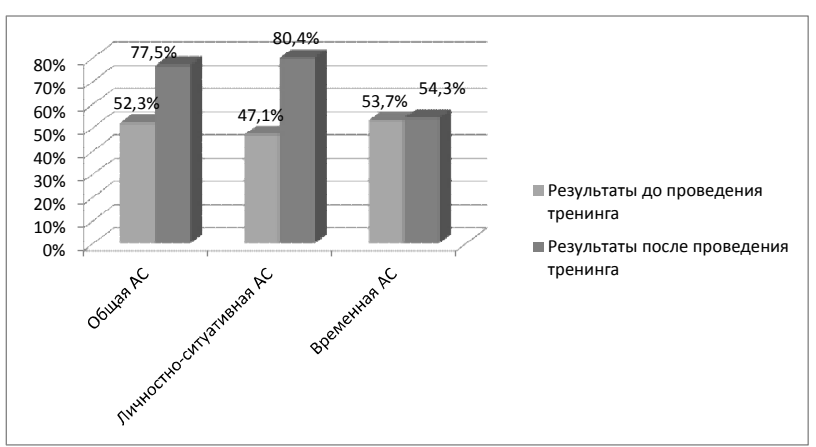

Рис. 2. Уровень антиципационной состоятельности до и после проведения тренинга

век поступает тем, у 31 \% подростков возникают сложности в определении поведения собеседника. Весомым аргументом результативности антиципационного тренинга служит то, что большинство подростков $(79,5 \%)$, в частности использующие стратегию сотрудничества, при агрессивных высказываниях в свою сторону могут воздержаться от подобного агрессивного ответа, ведут себя организованно, пытаясь разрешить проблемную ситуацию. Большинство подростков выбирающих адаптивные стратегии выхода из конфликта при оценке людей с легкостью избавляются от шаблонного и стереотипного мышления, напротив подростки, выбирающие стратегию соперничества подвержены влиянию стереотипов.

В ходе статистической обработки полученные данные были проверены с помощью корреляционного анализа Пирсона. Были вычислены значения корреляции по показателям стратегий выхода из конфликта по тесту Томаса, показатели общей и личностно-ситуативной антиципационной состоятельности до и после тренинга у представителей группы подростков. В ходе вычисления коэффициента корреляции Пирсона получились следующие результаты, приведенные в таблице.

\begin{tabular}{|c|c|c|}
\hline $\begin{array}{c}\text { Стратегии выхода } \\
\text { из конфликта } \\
\text { по тесту К. Томаса }\end{array}$ & $\begin{array}{c}\text { Общая анти- } \\
\text { ципационная } \\
\text { состоятельность }\end{array}$ & $\begin{array}{c}\text { Личностно-ситуа- } \\
\text { тивная антиципа- } \\
\text { ционная состоя- } \\
\text { тельность }\end{array}$ \\
\hline $\mathrm{r}=0,242(\mathrm{p}>0,001)$ & $\mathrm{r}=0,219(\mathrm{p}>0,01)$ & $\mathrm{r}=0,224(\mathrm{p}>0,01)$ \\
\hline
\end{tabular}

Это позволяет считать данные статистически значимыми, а значит действительно после проведения тренингововой работы наблюдается снижение уровня выбора стратегии соперничества, повышение выбора стратегии сотрудничества и полное отсутствие у испытуемых стратегии избе- гания ( $>>0,001)$, значительно повышается уровень общей и личностно-ситуативной антиципационной состоятельности. ( $\mathrm{p}>0,01)$.

Как подтверждает эмпирическое исследование - антиципационный тренинг по прогнозированию межличностных конфликтов в действительности является методом обучения подростов прогностическим способностям для умения определять и выявлять предконфликтную ситуацию и разрешать конфликт до его возникновения, а так же носит профилактический характер снижения конфликтности в подростковых группах. Антиципационный тренинг может быть рекомендован психологам-педагогам, школьным психологам и практикующим психологам при работе с подростками. Следует учитывать что тренинг в большей степени направлен на развитие коммуникативного уровня антиципационной состоятельности, в частности на умение правильно строить диалог при предконфликтном взаимодействии, умении анализировать невербальные каналы передачи информации, что является важным при прогнозировании межличностных конфликтов и в меньшей степени тренинг ориентирован на развитие временной антиципационной состоятельности. Дальнейшая доработка программы антиципационного тренинга может быть направлена на включение упражнений развивающих хронометрологические способности подростков, умение анализировать и следить за течением времени и на этой основе правильно моделировать события.

На сегодняшний день способность предугадать, спрогнозировать последствия будущих конфликтных проявлений дает возможность подросткам сдерживать антисоциальные действия. Развитое чувство ответственности и умение составить верный прогноз дальнейшего развития событий должны снижать уровень подростковой агрессии. ${ }^{6}$

Личностную составляющую готовности подростка к конструктивному поведению в конфликтной ситуации составляют эмоциональный («Я чувствую»), мотивационный («Я хочу»), когнитивный («Я знаю) и собственно поведенческий («Я делаю») компоненты готовности. Их формируют, с одной стороны, предметные потребности человека, связанные с включением в первичные и другие контактные группы, с другой стороны, соответствующие социальные ситуации.

\footnotetext{
6 Соловьева А.В. Психологическая защита в подростковом возрасте. Сущность, содержание, причины. М.: Флинта, Наука, 2013. 184 с.
} 


\section{Психология и психотехника 5(68) • 2014}

\section{Список литературы:}

1. Кулюткин Ю.Н. Индивидуальные различия в мыслительной деятельности взрослых и учащихся. М.: Педагогика, 1971. 112 с.

2. Маркова А.К. Психология усвоения языка как средства общения. М.: Просвещение, 1974. 225 с.

3. Менделевич В.Д. Антиципационные механизмы неврозогенеза. Казань: Медицина, 2011. 288 c.

4. Менделевич В.Д. Тест антиципационной состоятельности и прогностической компетентности-экспериментально-психологической оценки готовности к невротическим расстройствам // Социальноклиническая психиатрия. 2003. № 1. С. 35-40.

5. Сергиенко Е.А. Раннее когнитивное развитие: новый взгляд. М.: ИП РАН, 2006. 207 с.

6. Сиразиев М.Р. Антиципационная состоятельность личности подростка при разрешении конфликтных ситуаций // Современные проблемы науки и образования. 2014. № 2 (URL: http://www.scienceeducation.ru/116-12436).

7. Соловьева А.В. Психологическая защита в подростковом возрасте. Сущность, содержание, причины. М.: Флинта, Наука, 2013. 184 с.

\section{References (transliteration):}

1. Kulyutkin Yu.N. Individual'nye razlichiya v myslitel'noi deyatel'nosti vzroslykh i uchashchikhsya. M.: Pedagogika, 1971.112 s.

2. Markova A.K. Psikhologiya usvoeniya yazyka kak sredstva obshcheniya. M.: Prosveshchenie, 1974. 225 s.

3. Mendelevich V.D. Antitsipatsionnye mekhanizmy nevrozogeneza. Kazan': Meditsina, 2011. 288 s.

4. Mendelevich V.D. Testantitsipatsionnoi sostoyatel'nosti i prognosticheskoi kompetentnosti-eksperimental'nopsikhologicheskoi otsenki gotovnosti k nevroticheskim rasstroistvam // Sotsial'no-klinicheskaya psikhiatriya. 2003. № 1. S. 35-40.

5. $\quad$ Sergienko E.A. Rannee kognitivnoe razvitie: novyi vzglyad. M.: IP RAN, 2006. 207 s.

6. Siraziev M.R. Antitsipatsionnaya sostoyatel'nost' lichnosti podrostka pri razreshenii konfliktnykh situatsii // Sovremennye problemy nauki i obrazovaniya. 2014. № 2 (URL: http://www.science-education.ru/11612436).

7. Solov'eva A.V. Psikhologicheskaya zashchita v podrostkovom vozraste. Sushchnost', soderzhanie, prichiny. M.: Flinta, Nauka, 2013. 184 s. 